\title{
El pensamiento político de Hostos
}

Aunque el tema es tan amplio y deleitoso, por fuerza he de ser breve para cumplir con las exigencias de este programa de Centenario. Un capítulo de 78 páginas de mi ensayo sobre Hostos servirá de fuente a estas cuartillas que circunstancias agresivas me obligan a escribir.

Veinticuatro años, que parecían cuarenta, cumplía Hostos cuando hizo su entrada a la vida pública con $L$ a peregrinación de Bayoán. La vaguedad poética de esta novela, su atmósfera de ensueño, y su hoy opaco simbolismo no son un obstáculo para rastrear las alusiones políticas que van a su trabajo. Con este primer libro - grito sofocado de independencia, como decía el mismo Hostos- empieza su via-crucis. Amante de España, pero enemigo de sus desaciertos coloniales, pensó que las Antillas podrian formar una federación, y el paso previo era conseguir una amplia autonomía para estas islas dolorosas.

El punto de partida, que podemos marcar en el pensamiento político de Hostos, es su candorosa defensa a la independencia autonómica, "pero de tal modo que independencia no sea rompimiento de relaciones, sino creación de las que no existen hoy; de las relaciones del afecto y del interés material, moral y etnológico." En este primer paso de su orientación política, pensó que las Antillas podían sentirse como una prolongación de Es$20 \star$ 
paña, siempre y cuando tuviesen tun gobierno propio y decoroso. La monarquía española, las repúblicas de la América del Sur y la Confederación Antillana, o sea la familia peninsular, la continental y la insular, podrían, sobre bases de igualdad jurídica, formar la gran familia hispánica si Cuba y Puerto Rico disfrutasen de la soberanía imprescindible para lograr, con Santo Domingo, la Confederación Antillana.

Para defender este ideal abandonó sus estudios de derecho, subió a las tribunas, escribió en las revistas, fundó periódicos, discutió en el Ateneo, comprometía a sus amigos políticos y se entregó de lleno a la propaganda liberal española junto a Azcárate, Olózaga, Pi Margall, Salmerón, Castelar y otros.

Así le vió D. Benito Pérez Galdós cuando los sangrientos sucesos estudiantiles de la noche de San Daniel - io de abril de 1865 - discutiendo en uno de los pasillos del Ateneo: "En el pasillo grande del Ateneo -dice Galdós en Prim- permanecían dos corrillos de trasnochadores. El más nutrido y bullicioso ocupaba el ángulo próximo a la puerta del Senado; allí analizaba la bárbara trifulca un antillano llamado Hostos, de ideas muty radicales, talentudo y brioso".

Ia autonomía como fómula de conciliación, fué perdiendo terreno en su pensamiento político a medida que la crisis y la opresión aumentaban en las Antillas. Ante las persecuciones injustas, los abusos del poder, las incumplidas promesas de reformas, la mordaza de prensa, las contribuciones excesivas, los atropellos a la dignidad y al civismo, en I868 Puerto Rico dió su Grito de Lares y Cuba el de Yara. Y el evolucionista que había en Hostos, desesperado y roto, destrozada su fe por justificadas rebeldías, cansado de aguardar lo prometido, se tornó ra. dical y buscó en la revolución el triunfo de su ideal federativo. He aquí el segundo aspecto de su pensamiento politico.

"Puerto Rico no era un campo propicio para la lucha armada; las angustias de largos años, la docilidad de sus masas sufridas, el reciente y estruendoso fracaso de la revolución de Lares, sus 
condiciones geográficas, anticipaban la derrota. Había que pensar en Cuba, tan abnegada y rebelde, a la cual defendía Hostos desde 1863 sin jamás haber estado en ella. La revolución encontraría apoyo y éxito en la Antilla mayor, y libertada Cuba, vendría inevitablemente la libertad de Puerto Rico y la de las islas menores. Ese era el plan de Hostos para lograr al fin la Confederación Antillana, sin la cual se debilitaría la de todas las Repúblicas de América. Era un ideal insular y continental, que tuvo origen en la mente luminosa de Simón Bolívar y que con Hostos, alentaron Betances, Máximo Gómez y luego Marti”".

Hostos procedió por etapas claras y definidas. Del enstieño pasó a la decepción, de la decepción a la desesperación, de la desesperación a la revolución. Proponía una fraternidad honrosa y todos la encontraban imposible; pedía reformas y le contestaban con evasivas, y mientras tanto el dolor de su patria ya no le cabía en el corazón.

El zo de mayo de 1869 , estando aún en Madrid, hace examen de conciencia y escribe en su Diario: "Ayer me interrumpí para escribir a mi padre. Decíale yo que era necesario prepararse para verme arrostrar todas las eventualidades del apostolado de justicia y libertad que he querido hacer en favor de nues. tra patria, $y$ deseando que el fin por realizar y el deber por cumplir estuvieran sancionados por la bendición paterna, discutía con él mi posición en España y la necesidad de ir a Nueva York para desde allí, y probablemente desde Cuba, intentar con esfuerzos personales, con las armas en la mano, la conquista de la independencia".

Cuatro meses después lo encontramos en París con rumbo a la manigua. La Junta Revolucionaria de Nueva York preparaba una expedición para el to de octubre y abandona París con rumbo a Nueva York para ofrecer su brazo a la idea que tenía en el cerebro. Pero la junta estaba en bancarrota y el proyecto fracasó, minado de pequeñeces personales. Fué tal la 
actividad desplegada para unir voluntades dispersas y tan tenaz su propaganda, que el revolucionario Basora afirmaba sin enpacho: "La independencia volverá loco a Hostos".

$\mathrm{Y}$ como tenía condición de labriego y mano generosa de sembrador, miró en surcos abiertos a la América Hispana y allá se dirigió en 1870 , en romería patriótica de cuatro años, para sembrar confianzas en la causa y conseguir para Cuba el apoyo moral y material que la revolución necesitaba. Cartagena, $\mathrm{Pa}$ namá, el Callao, Lima, Santiago de Chile, Valparaíso, Buenos Aires, Córdoba, Rosario, Santos, Río de Janeiro, Saint Thomas le recibieron como a apóstol, sin predecir si sería héroe o mártir.

"No tuvo la revolución cubana un propagandista más activo, un revolucionario más entusiasta, un amigo más sincero y desinteresado que Hostos. Durante cuatro años multiplica su actividad en el nuevo continente, allegando recursos bélicos, exaltando el patriotismo, organizando comités, fundando periódicos, escribiendo editoriales, pronunciando discursos y conferencias públicas y privadas, publicando folletos, sin dejar por esto de rendir eficaces servicios a las repúblicas que visitaba".

$\mathrm{Ni}$ el halago, ni el soborno, ni la gloria ni el bienestar personal le detuvieron en su marcha. "En Chile, como antes en Cartagena y en el Perú, volvió a sentir el natural reclamo de una pasión amorosa, que una vez más supo dominar. Estas tragedias afectivas de la juventud quedaron veladamente recogidas en las páginas de su Diario. La sinceridad de su apostolado, el respeto que se debía a sí mismo y a las ideas que defendía, el cumplimiento de un deber de sacrificio que luego no iban a apreciar, le obligaron a rechazar todas las tentativas en que el amor puso a prueba su tesón de patriota. Ni la esperanza de felicidad vislumbrada en un matrimonio conveniente, ni la certidumbre de crearse una sólida posición, ni la paz ni el sosiego con que invita a los hambrientos de cariño la santidad hogareña, pudieron inducirle a la renunciación. En la cruz de su deber, con la protesta 
de los instintos mutilados, crucificó Hostos sus afectos de juventud, para continuar sin impedimento la ruta irremediable".

$\mathrm{Y}$ cuando D. Vicente F. López le ofrece en la Universidad de Buenos Aires una cátedra de filosofía, el intacto patriota que había en Hostos, responde sin titubeos: "Yo he venido a la América latina con el fin de trabajar por una idea. Todo lo que de ella me separe, me separa del objeto de mi vida". Una vez más probaba con su abnegación la lealtad a sus principios.

Treinta y urı años contaba cuando inició su peregrinación de Bayoán por la América Hispana. A su regreso a Nueva York en I874, tenía un siglo de experiencia. Se le bronceó el carácter, se le hizo musculoso el pensamiento, se le agrandó el corazón. Su voz quedó temblando en todos los ódos y su ideal prendido en todas las conciencias. Porque era recto, cabal, hombre sin dobleces, pundonoroso, digno, acrisolado y bueno.

"Hondos fueron los sufrimientos del desgraciado Hostos, que no queriendo utilizar las dádivas de nadie, ayudaba a su miseria muchos días con agua de tamarindo. Había despreciado repetidas veces una posición desahogada en Sudamérica; escaseaba el trabajo; no admitía las finezas de un hermano que anónimamente le había socorrido con 20 dólares. Descubierto el remitente, devolvió el dinero. $\mathrm{Y}$ cuando el general Aguilera le hizo entrega de roo dólares para que se costeara los gastos preliminares de una próxima exposición, fué tan rotunda su negativa, que hasta llegó a encolerizarse con el general, creyendo que compraba sus servicios. Se había hecho a sí mismo el juramento de no aceptar un solo centavo de Cuba. A duras penas sostenía su empeño libeŕtario con el dinero que ganaba dando clases de francés, haciendo traducciones o escribiendo para la prensa. El 29 de abril de 1875 se cumplen nuevamente sus deseos de ir a pelear por Cuba. Se embarca en una expedición del general Aguilera que salió desde Boston en el Charles Miller, viejo velero de pobres condiciones marineras. A los tres días de navegación un temporal que subía furioso de los trópicos, desman- 
teló el velero y haciondo agua pudieron salvarse de la muerte recalando en un puerto de Rhode Island.

Pocos días después, escribe en su Diario, i 2 de mayo de 1875 : "Han venido a preguntarme si estoy dispuesto otra vez a cmprender la aventura. He dicho que sí. Voy preparándome para salir pasado mañana. Será una locura, pero es preferible ser tun loco a vivir entre esta gente".

Y en carta que le dirigió el general Aguilera, le decía:

"Usted Hostos ha hecho más que yo, amigo mío, en obsequio de la libertad de las $\Lambda$ ntillas. Ud. se lanzó desde el principio de nuestra revolución, sin consultar sus sentimientos más caros, a los azares de una emigración larga y penosa por toda la América del Sur y su cficaz propaganda nos ha producido ya muy buenos frutos. Posteriormente, con su carácter decidido y entusiasta por la libertad de Cuba, me ofreció usted aconpañarme para compartir con ntestros hermanos los azares de la guerra. Nos embarcamos en el Charles Miller y pasamos jurltos los sinsabores de esa navegación tan corta como desgraciada".

Pero Hostos no escarmienta. Y vuelve a peregrinar por Santo" Domingo, Puerto Plata, Saint Thomas, la Guayra, Caracas, Puerto Cabello, Nueva Esparta. En Saint Thomas le sorprende cin 1878 el desgraciado Pacto del Zanjón, que poniendo fin a la guerra de los Diez $A$ ños, puso en peligro la independencia de Cuba. Agobiado por la tristeza, aceptó el cturo golpe de la realidad política y desde entonces (1878-1898) se dedicó a la enseñanza, primero en Santo Domingo, después en Chile.

Durante 20 años el político que había en él, perturbaba el sosiego del maestro. Cuando en 1895 supo que Martí había entrado en Cuba, se puso de nuevo en movimiento, escribió en los periódicos, pronunció conferencias, fundó sociedades y volvió a sentir el fervor de la propaganda; y sacrificando su bienestar y el de su numerosa familia, el 27 de abril de 1898 , dos días después de declararse la guerra hispanoamericana, renuncia la rectoría del Liceo Amunátegui y sale para Nueva York a ofrece: 
sus servicios al Partido Revolucionario Cubano, del cual era Delegado en Chile. Previendo las consecuencias que el rompimiento de hostilidades pudiera traer a Puerto Rico, to abandona todo y sale de Valparaíso cuando aún no sabía sonacto el primer cañonazo.

Dificultades en la transportación y exigencias de la propaganda le hacen llegar a Nueva York el 16 de julio, y dos días después la escuadra americana salió de Santiago de Cuba para tomar a Puerto Rico. Y cuando el 25 de ese mès, inesperadamente desembarcan las tropas por Guánica, Hostos se encontraba en Washington en compañía de D. Roberto H. Todd y el Dr. Henna conferenciando con el Secretario de Estado.

Consumados los hechos, marchó a Nueva York para jugarse la última carta. Para asegurar la independencia de Pierto Rico post-bellum, trabajó porque el gobierno americano reservase al pueblo puertorriqueño el derecho de decidir su suerte mediante un plebiscito.

"Ejerciendo nuestro derecho natural de hombres — lecía en el Manifiesto publicado- que no podemos ser tratados como cosas; ejerciendo nuestro derecho de ciudadanos accidentales de la Unión Americana, que no pueden ser compelidos contra su voluntad a ser o no ser lo que no quieren ser, o lo que aspiran a ser, iremos al plebiscito. En los Estados Unidos no hay autoridad, ni fuerza, ni poder, ni voluntad que sea capaz de imponer a un pueblo la vergüenza de una anexión llevada a cabo por la violencia de las armas, sin que maquine contra la civilización más completa que hay actualmente entre los hombres, la ignominia de emplear la conquista para domeñar las almas".

Repetía Hostos con el presidente McKinley que "tuna anexión forzada es una agresión criminal". Y $Y$ para laborar por el bienestar de Puerto Rico y asegurar su propia determinación al través de un futuro plebiscito, organizó en Nueva York la Liga de Patriotas y en septiembre embarcó hacia esta isla para plan- 
tear ante el gobierno militar una cuestión de derecho constitucional.

"El objeto político de la Liga, es conseguir el cambio del gobierno militar por el civil; el establecimiento del gobierno tan pronto como el Congreso se reúna; el enaltecimiento de Puerto Rico a la categoría de Estado; reserva del derecho de plebiscito para cuando la situación política favorezca ese propósito".

No subordinaba a los partidarios de la independencia absoluta como lo era él, ni a los que defendían la anexión, el porvenir de Puerto Rico, sino que después de un aprendizaje práctico de gobierno democrático, el pueblo puertorriqueño quedaba autorizado para definir su propio Status. "Yo no quiero la anexión - decía en un artículo-. Lo que yo quiero, para bien de mi patria, para gloria de la nación americana, y para el triunfo de instituciones que han hecho de los Estados Unidos el pueblo representativo de la libertad jurídica, es un gobierno temporal que eduque en el ejercicio de los derechos civiles y políticos a los puertorriqueños y que les ponga en aptitud de gobernarse por sí mismos y de concurrir en el futuro como amigos y aliados agradecidos del pueblo de la Unión, y a los altos destinos que les esperan".

Para defender estos postulados embarcó Hostos con el Dr. Zeno Gandía y con el Dr. Henna que vivía en Nueva York, formaron la primera comisión puertorriqueña que fué a Washington.

"Hostos - ha dicho el Dr. Zeno- fué oído como un prócer; hizo volver la cara a las más eminentes personalidades; Mr. Hay, Secretario de Estado, escritor y poeta lírico, le llamó el arrogante hombre del trópico. En aquellas jornadas secundadas por los brillantes trabajos de nuestro gran compatriota Henna, dos figuras se mostraron erguidas en el gran proscenio de Washington: William McKinley, el presidente vacilante, y Eugenio María de Hostos reclamando con sus compañeros de comisión, el reconocimiento del derecho de los puertorriqueños a una patria libre y la sanción a un plebiscito que expresara cuál era su voluntad. 
Esta comisión a Washington -termina diciendo el Dr. Zenofué el último gesto de Hostos. Fui testigo y declaro que fué inmarcesible".

$\mathrm{Y}$ para destruir dudas, y aclarar erróneas interpretaciones, en los últimos años de su vida se reafirmaba en su ideal con estas palabras meridianas: "Debemos declarar y así lo hacemos, una vez por todas, que nunca hemos pedido ningún otro régimen, gobierno o administración que no sea el de nosotros mismos".

Este es pues, señoras y señores, dentro del abreviado espacio que me concede este programa, el pensamiento político de un hombre que ¡siempre lo dió todo y nunca pidió nada!

Antonio S. Penkeira. 
